\title{
Effect of Knowledge and Compliance of Health and Safety Information on Construction Sites Workers' Safety in Nigeria
}

\author{
Ranti T. Adebiyi ${ }^{1 *}$, Olubola Babalola ${ }^{2}$, Ganiyu Amuda-yusuf ${ }^{1}$, Shehu A. Rasheed ${ }^{1}$, Theophilus O. Olowa ${ }^{1}$ \\ ${ }^{1}$ Department of Quantity Surveying, University of Ilorin, Ilorin 240103, Nigeria \\ ${ }^{2}$ Department of Quantity Surveying, Obafemi Awolowo University Ile-Ife, Ile-Ife 220282, Nigeria
}

Corresponding Author Email: adebiyi.rt@unilorin.edu.ng

https://doi.org/10.18280/ijsse.100215

Received: 18 June 2019

Accepted: 13 January 2020

\section{Keywords:}

accident, compliance, health and safety, information, knowledge, Nigeria, site workers

\begin{abstract}
Construction sites have been identified as one of the most hazardous places to work due to high level of health and safety risks. Information on health and safety is therefore required to educate the participants on how to achieve safe working environment. This study therefore examined and analysed level of knowledge and compliance with information on health and safety and the effects on the safety of construction workers in Nigeria. Findings from the study revealed that the workers have average knowledge of health and safety information but demonstrated low level of compliance. The result also established a very strong positive correlation between compliance of health and safety information and safety of workers. However, when the significance of the correlation was tested, the result implied that though there was a positive relationship between compliance and safety of workers, the relationship was not significant. Practically, this meant that compliance alone cannot substantially guarantee workers safety.
\end{abstract}

\section{INTRODUCTION}

Construction industry is experiencing more complex, multifaceted and technically inclined projects which involve multidisciplinary and interrelated operations. These operations required the participation of various categories of workers on construction sites. Safety of these workers is paramount to achieving success in any construction project as virtually all operations on sites are dependent on the workers for implementation $[1,2]$. It is only when these workers are in a sound state of mind and are physically healthy that work can go on smoothly. This makes the safety of workers to be a priority.

Careful attention should be paid to the safety of these workers by updating them on Health and Safety (H\&S) information, such as regulatory requirements, nature of hazards, safe working practices and accident preventive measures. Knowledge of $\mathrm{H} \& \mathrm{~S}$ information is important in ensuring safety of construction workers, as researchers have hypothesized that a positive correlation exists between awareness of H\&S information and safety of construction workers [3-6]. This assertion is also supported by Okoye et al. [7] that availability of information on $H \& S$ minimizes accidents and injuries on construction sites. It is therefore vital to note that construction workers are required to be furnished with adequate knowledge of H\&S information.

A noteworthy difficulty presently confronting the workers includes prevalence accidents and ill-health on construction sites. This calls for an intensive investigation into the level of knowledge and compliance with H\&S information by the construction workers [8]. Udo et al. [9] revealed that the neglect of H\&S information on sites have considerable impact of workers' productivity and performance. Non-compliance with H\&S information is a major contributor to the poor safety and health conditions on construction sites. This is because knowledge of H\&S information is not a standalone step for improving safety of workers, there must be a strict compliance [3].

The issue of whether these workers have adequate knowledge on H\&S information and whether they comply with $H \& S$ rules and guidelines on site come to fore. Even if there is adequate H\&S information, knowledge and compliance among construction workers, will these translate to their safety on construction sites? It is against this background that this study was carried out to assess the level of knowledge and compliance with H\&S information and safety of workers on construction sites in Nigeria by: examining the level of knowledge of H\&S information; determining the workers compliance with $H \& S$ information; identifying factors influencing level of compliance; investigating the effects of compliance with $\mathrm{H} \& \mathrm{~S}$ information on safety of the workers.

\section{GLOBAL SITUATION OF HEALTH AND SAFETY ON CONSTRUCTION SITES}

Construction industry is one of the most hazardous industries globally because of the frequent and high rates of accident and ill-health on construction sites [10,11]. The occurrence of accidents is grave concern for both practitioners and researchers all over the world [12]. Among all major industries, construction workers face the highest number of the risks of occupational injuries, illnesses even death around the world. Higher mortality rates on construction sites remain a global major concern. Occupational Health and Safety (OHS) statistics presented by different researchers revealed that, the injury and fatality rate on construction sites is very high in 
comparison with other sectors of industry in the majority of countries [13-15]. Though, findings from a study carried by Sunindijo and Zou [16] revealed that accidents and fatality rates were found to be higher in some countries than others.

In developed countries like Japan, United Kingdom and the United States, about $20 \%$ of industrial fatal accidents in 2017 were from construction activities [17-19]. Similar study by Shafique and Rafiq [14] revealed that construction industry is one of the most fatal industries in Hong Kong. Notably, about $76 \%$ of industrial fatalities in 2017 took place only in the construction industry [20]. Workplace Safety and Health Institute (WSH)'s report states that the number of fatalities from occupational accidents in Asia was higher from all five regions [21]. Besides, the WSH's report also identified that construction industry as one of the most dangerous industries in the world. Usually, most of the accidents on construction sites are due to the unawareness of the safety precautions [22]. But most of the developed countries are trying to reduce the horrific damages and losses from construction accidents by implementation of stricter laws and regulations [10].

Other research conducted in developing countries corroborate evidence of this relatively high proportion of accidents on construction sites [23]. Bangladesh has one of the most accident-prone construction industries among all the developing countries of the world [10]. Every year, an average of 150 persons died and thousands of people get injured due to the accidents in construction sites in Bangladesh. In Ghana, Kwofie [23] reported a poor state of $H \& S$ on Ghanaian construction sites. In a similar study by Amissah et al. [24] occupational injuries have been identified among the leading causes of death in Ghana. Specifically, about $10 \%$ of occupational accidents reported in 2018 were from construction-related injuries. Machfudiyanto et al. [25] conducted a study to evaluate occupational injuries among workers in Indonesia, construction sector accounted for the highest number of work-related accidents, with $32 \%$.

The developing countries are the extreme victim of construction accidents because they have no strict regulation or no strict practicing of construction safety where both authorities and employees are not aware of construction safety issue $[10,15]$. Construction industry in developing countries has performed far below the expectation in the areas of $H \& S$ because it involves more workers per activity on sites. Typically, 2 - 10 times as many workers per activity compared with developed countries [26]. Farooqui et al. [27] presented a good picture of H\&S performance of developing countries. Unsafe conditions exist on many sites, both large and small, workers undertake a number of risk and are subjected to numerous hazards, no training programs for the staff and workers exist, hazards are not pointed out, and no safety meetings are held. Employees are required to learn from their own mistakes or experience. In addition, lack of medical facilities, shanty housing and substandard sanitation tend to exist on remote projects in most developing countries.

\section{HEALTH AND SAFETY ON CONSTRUCTION SITES IN NIGERIA}

$\mathrm{H} \& \mathrm{~S}$ situation on construction sites is quite pathetic in Nigeria because many people have met their ultimate death while others have become permanently crippled from construction related injuries [28]. Statistically, little information is available on the number of accidents rate that happen on construction sites annually, because contractors neither report accidents at appropriate ministry nor keep proper records on accidents [29]. However, the limited information made available by Inspectorate Division of the Federal Ministry of Labour and Productivity indicates that Nigeria's construction industry is responsible for about $7.5 \%$ of all occupational accidents, $49.5 \%$ of these injuries were fatal, $12.2 \%$ were partial disabilities and $7.4 \%$ of minor injuries [30].

The H\&S performance of construction industry remains a glaring challenge in its efforts to tackle the developmental initiative in Nigeria. Muhammad et al. [31] opined that Nigeria falls within the category of countries having no adaptive $\mathrm{H} \& \mathrm{~S}$ laws and regulations, where organizations allocate little resources to H\&S management, rarely keep, report, or release accurate records of accidents and injuries on site, leading to poor health and safety performance.

The pathetic situation of $H \& S$ on construction sites in Nigeria made [5] to conclude that the constructing organizations should increase level of awareness of H\&S information. The rate of accidents on construction sites therefore, calls for an intensive investigation on level of awareness of information on H\&S among construction workers. Today, it is a basic right of every worker to have a safe and accident-free workplace. Many countries in the world started working to reduce the accident rate in the construction industry and they had shown success in various ways to reduce or even eliminate accidents on the sites. But Nigeria is backward from them. Nigeria has to work on H\&S seriously to reduce accident rate on construction sites. Numerous studies have demonstrated that a fairly large percentage of fatal accident on construction sites could have been eliminated, reduced, or avoided if the workers are aware of likely hazards, safe working practices and accident preventive measures on the particular site.

\section{HEALTH AND SAFETY INFORMATION}

In the modern construction environment, information on $\mathrm{H} \& \mathrm{~S}$ is a very sensitive construction organization's responsibility [32]. Agwu [33] noted that information on H\&S is a performance-oriented approach to construction by establishing a safe working environment that is consistent with peak performance and continuous improvement. Adebiyi et al. [32] pointed out that the organization should by law communicate a large amount of information to the workers, site visitors and the general public. To avoid information overload and confusion it is recommended that the four R's of rules, regulations, responsibilities and risks should be outlined in the contents of information communicated. Safety rules include the organization's philosophy and commitment to safety of all workers, site visitors and general public. Regulations must be communicated in a clear, concise and correct manner if $\mathrm{H} \& \mathrm{~S}$ objectives are to be achieved. All workers should be fully aware of their responsibilities and should be provided with all information necessary to carry them out in a safe manner. Organization should also provide information, instruction and training to the workers so that they can carry out their responsibilities effectively. Workers must be fully aware of H\&S risks, measures to prevent them and emergency procedures in event of risks being realized.

$\mathrm{H} \& \mathrm{~S}$ information as highlighted by [7, 32, 34, 35] are as follows: company's health and safety policy, risk associated 
with the current job, the potential risks to the health and safety of the workers, location and nature of hazard in the workplace, preventive and protective measures for the risks and hazards on sites, procedures for the safe operation, use, maintenance and replacement of protective equipment, site rules, injury and incident reporting procedures, procedures for resolving health and safety issues, disciplinary policy, the identities of those who have a role within the organization's H\&S management system, emergency and first aid procedures.

\section{KNOWLEDGE OF HEALTH AND SAFETY INFORMATION}

Knowledge involves an awareness or understanding gained through experience, familiarity or learning [36]. According to the study [37] knowledge creation is dependent upon information, the development of relevant information requires the application of knowledge. Akinwale et al. [38] pointed out that knowledge of $\mathrm{H} \& \mathrm{~S}$ information on how to reduce risk factors among workers will enhance site safety. Safety knowledge therefore, encompasses awareness of occupational H\&S information, including an evaluation of occupational $\mathrm{H} \& \mathrm{~S}$ programmes in the organization.

Sources of safety knowledge according to the research [7], include incident investigation, teamwork, collaborations and survey of safety culture. The role of trainings in promoting H\&S knowledge has also been highlighted by Akpan [39]. Kumar \& Bansal [40] stated that effective safety knowledge among construction professionals reduces accidents and directly or indirectly reduces project cost. The above view is supported by Kamar et al. [41]. However, Sunindijo and Zou [42] suggested that employees, including project personnel, should be equipped with safety skills and with necessary H\&S knowledge to enable them to work safely and to encourage others to do the same. As such, construction organizations should advance a climate which values safety learning. On this basis, Adebiyi et al. [32] inferred that safety learning should not only be considered as an acquisition of knowledge through instructions and training in classrooms or other formal settings rather safety should be considered as the final outcome of a dynamic and collective construction process. In this case, a safe workplace is the result of constant engineering of diverse elements, such as knowledge and skills, equipment, and social interactions, which are integral to the work practices of various project stakeholders.

\section{CONSTRUCTION HEALTH AND SAFETY COMPLIANCE}

Compliance is described as applying measures designed to comply with legal requirements with the regulator being primarily more concerned with improved outcomes than prosecution results [43]. According to Agwu [33], compliance with H\&S legislations can increase productivity in industries by reducing accidents. Frequent occurrence of accidents on construction sites calls for an intensive investigation into the level of knowledge and compliance of $H \& S$ information by construction workers [5]. This prevailing occurrence of accidents on sites can be adduced to the degree of compliance with $\mathrm{H} \& \mathrm{~S}$ information which was described as being very low in Nigeria [30].

Lack of strict enforcement of H\&S regulations enables non- compliance with the regulations. Umeokafor et al. [30] stated that non-compliance to $\mathrm{H} \& \mathrm{~S}$ regulations is a major contributor to the poor state of $H \& S$ in Nigeria. Moreover, Williams et al. [43] expatiated on the factors contributing to non-compliance to $H \& S$ information as bribery and corruption, fear of legal sanctions, higher profit margin, inadequate funding, inadequate staff and workplace issues, management commitment, neglect of human rights, perception of stakeholders in the industry, wrong beliefs, reputation of firms and the type of tendering process adopted. Additionally, the Nigerian building construction sites are bombarded with inexperienced construction operatives, where site workers carry out operations with no regards to regulations on safety, most essentially in small and medium-scale firms.

The use of safety items is refuted by most workers, with much disregard given to it as a result of lack of knowledge, lack of enforcement of safety regulations, inconveniences created by putting on personal protective equipment and poor safety culture.

It is, nevertheless, saddening in noticing that the Federal Ministry of Labour and Productivity (Inspectorate Division) which is responsible for overseeing the OHS in Nigeria has been found inefficient [43]. Against this backdrop, Williams et al. [43] traced the origin of the regulations of OHS to the United States (US) and United Kingdom (UK) from where greater part of the regulations adopted in Nigeria was extracted. In addition, Umeokafor et al. [30], reported that Factories Act of 1990 which the country adopts is exclusive of the construction industry thereby making the regulations unenforceable in the construction sites. This has made construction industry remained unregulated, and consequently leaving the implementation of the UK/US adopted regulations at the discretion of the practicing construction firms.

\section{METHODOLOGY}

The main objective of this study is to assess effect of knowledge and compliance with H\&S information on construction sites workers' safety. To achieve the objective, a comprehensive literature review was carried out to identify $\mathrm{H} \& \mathrm{~S}$ information available on construction sites. A total of twenty-three (23) contents of H\&S information identified from previous studies were adopted as basis for questionnaire design. The target population was workers on sites of construction organizations that are registered with Lagos State Public Procurement Agency (LSPPA). LSPPA maintains a database of registered contractors and to describe their classification and categorizations based on contract value. According to LSPPA Directory (2019), registered contractors were classified into five (5): Class A, B, C, D and E as shown in Table 1. Lagos State was chosen for the study because of its reputation as the major hub of construction activities in Nigeria [44].

Table 1. Classification of registered contractors under LSPPA

\begin{tabular}{cc}
\hline Class & Contract Value/Threshold ( $\#$ ) \\
\hline A & 0.5 Million - 10 Million \\
B & 10 Million - 100 Million \\
C & 100 Million - 250 Million \\
D & 250 Million - 1 Billion \\
E & Above 1 Billion \\
\hline
\end{tabular}


The construction sites of contractors registered under categories D and E were identified for this study. These categories of contractors are high caliber, well-structured and noted for executing projects of huge contract sums with records of $\mathrm{H} \& \mathrm{~S}$ policies and a wide variety of workers on sites. The pilot survey for the purpose of this study revealed that there were fifty five (55) active construction sites in the study area as at the time of study. Therefore, this study adopted the purposive sampling technique to select the sample size of fifty five (55) construction sites and randomly select any three (3) trade-men from bricklayers, carpenters, iron benders, electricians and plumbers in the study area. Total sample size was one hundred and sixty-five (165). The questionnaire was structured and divided into two sections: the first section was designed to get information about personal data of the respondents to guarantee reliable and quality information. The second section addressed specific objectives of the study. This section contains twenty three (23) contents of H\&S information, twenty six (26) statements on compliance with $\mathrm{H} \& S$ information and seventeen (17) statements on factors influencing level of compliance on site workers safety. In each of the statements, respondents were required to express their opinion on a five point Likert-type scale, where $1=$ very low, and $5=$ very high .

Mean Score Ranking and Standard Deviation were adopted for analysing level of knowledge, compliance and factors influencing level of compliance while Pearson's ProductMoment Correlation Coefficient was used to establish the relationship between level of compliance and safety of workers.

\section{DATA ANALYSIS AND DISCUSSION OF RESULTS}

A total of eighty-four (84) copies of properly completed questionnaire, representing $52 \%$ of the total number were returned. The results in Figure 1 revealed type of trades of each worker surveyed. The Figure showed that $27 \%$ of the workers were bricklayers/plasterers, $18 \%$ carpenters/joiners, $7 \%$ roofers, $6 \%$ electricians and also $7 \%$ plumbers. Other workers included $8 \%$ glazers, $4 \%$ painters/decorators, $7 \%$ welders and $7 \%$ labourers.

Figure 2 presents the type of employers that engage the workers. The results indicated that about $58 \%$ of the workers were employed by sub-contractors while $37 \%$ were employed by the main contractors.

Modes of engagement of the workers were presented in Figure 3 . The findings revealed that about $30 \%$ of the workers were engaged on part-time, while $61 \%$ were on full-time engagement. The remaining $9 \%$ are on daily basis.

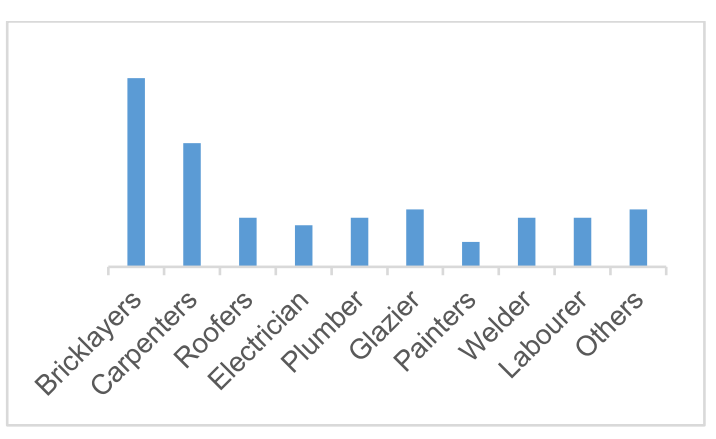

Figure 1. Name of trade of site-operatives

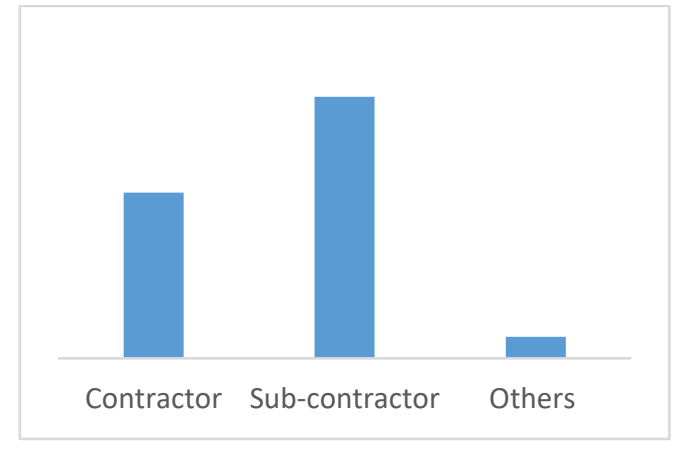

Figure 2. Type of employers in organization

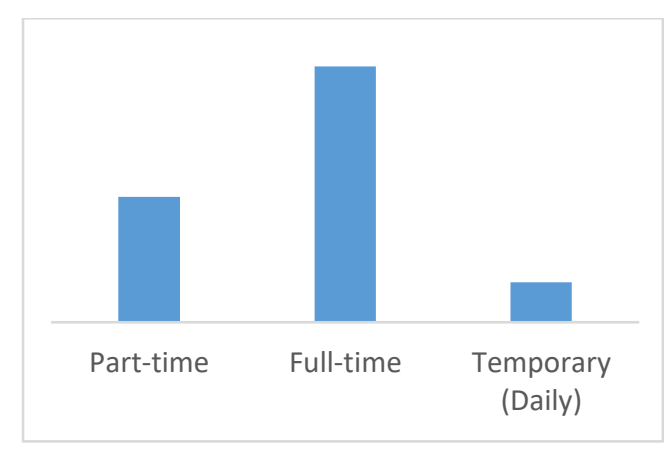

Figure 3. Modes of engagement

Figure 4 presents the highest education qualification of the workers. This result revealed that about $55 \%$ of the workers have a very low level of education, (not more than primary education), which can be a challenge to understanding information on $\mathrm{H} \& \mathrm{~S}$.

Although majority of workers have had little education, their levels of experience on construction sites are commendable (about 54\% have more than 10 years construction experience) as revealed by Figure 5 .

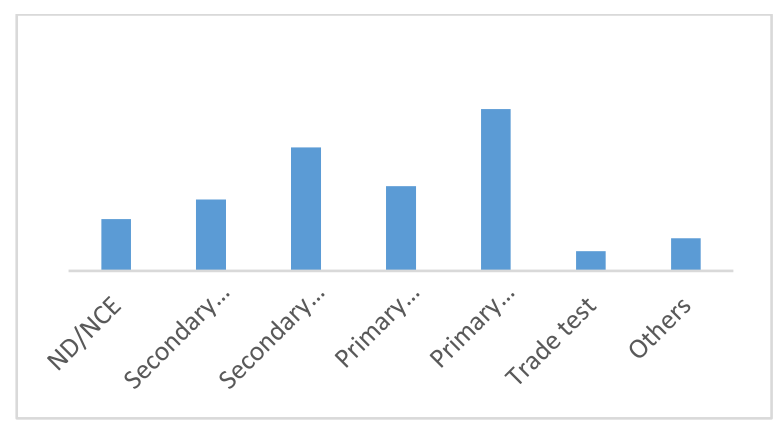

Figure 4. Highest education qualification

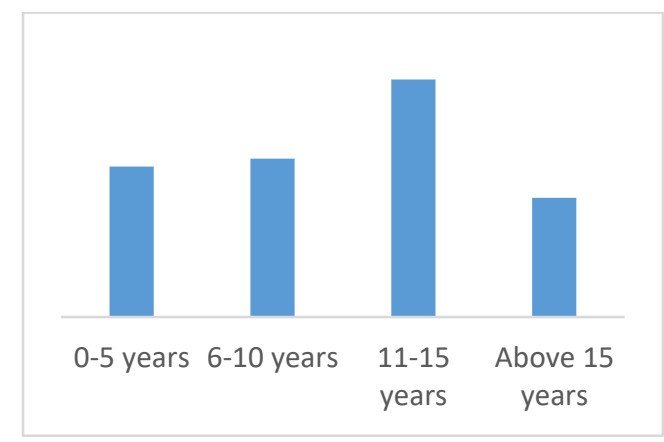

Figure 5. Years of experience on construction sites 


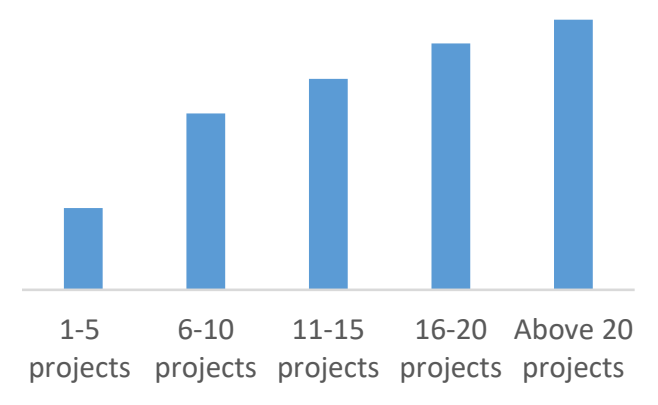

Figure 6. Number of projects undertaken in the last 10 years

Furthermore, Figure 6 revealed numbers of projects the workers have participated in the last ten years. Not less than $74 \%$ of the respondents had worked on more than ten (10) projects. It is therefore plausible to conclude that data provided are credible and reliable because of the experience of the respondents.

\subsection{Knowledge of health and safety information by the construction site workers}

Table 2 presents the results of the ranking of level of knowledge of H\&S information. The results show that there was average level of $\mathrm{H} \& \mathrm{~S}$ knowledge among the workers on construction sites in Lagos State. This is similar to the study carried out by Kolo [1] in Anambra State, Nigeria where there was a moderate level of H\&S knowledge among the workers in the state. However, the respondents indicated that they have knowledge of H\&S information such as first aid procedures with Mean Score (MS) of 3.89, safety signs and symbols (MS of 3.69), the use, maintenance and replacement of protective equipment (MS of 3.53), procedures for the safe operation on site (MS of 3.40) and site regulations (MS of 3.38).

Other known H\&S information were: preventive and protective measures for risks and hazards on site (MS of 3.35), company H\&S policy (MS of 3.33), best practices in the company (MS of 3.31), safety performance (MS of 3.29) and site rules (MS of 3.28) as presented in Table 2. Table 2 also revealed that information on $\mathrm{H} \& \mathrm{~S}$ such as location of hazard (MS of 2.92), injury and incident reporting procedures (MS of 2.91 ), accident statistics and records (MS of 2.83), accident investigation (MS of 2.78) and minutes of safety review meetings (MS of 2.68) were not well known by the respondents as indicated by the mean scores below average mean score of 3.19 .

\subsection{Level of compliance of health and safety information by the construction workers}

Table 3 presents the results of the ranking of compliance with $\mathrm{H} \& \mathrm{~S}$ information. It was revealed that the average MS for the level of H\&S compliance by construction workers was low (2.47). This was an evidence of low level of compliance with $H \& S$ information by construction workers. Although the results on Table 3 indicated that the workers complied a little with first aid treatment (MS of 3.33), possession of basic safety training (MS of 3.31), handling of safety equipment (3.29), safety induction/project briefings (MS of 3.28) and communication of potential risks among themselves (MS of 3.26).

The results further revealed that accident or injuries on sites were rarely investigated (MS of 1.94), recorded (MS of 2.00) or reported (MS of 2.14). There was generally no provision for means of escape in case of emergency (MS of 2.03). Most importantly the findings indicated that there were no strict monitoring and enforcement of safety policy (MS of 2.12).

These findings from Tables 2 and 3 indicated that the workers have average knowledge on H\&S information but level of compliance with the information was low. So having knowledge of H\&S information alone without corresponding compliance with the information cannot guarantee workers safety. Compliance can therefore be achieved through monitoring, persuasion and even sanctions on defaulters in addition to management commitment. This will therefore, ensure better safety of workers on sites.

Table 2. Level of knowledge of health and safety information

\begin{tabular}{|c|c|c|c|c|}
\hline Health and Safety Information on Construction Sites & Valid & Mean & Standard Deviation & Rank \\
\hline First aid procedures & 84 & 3.89 & 0.896 & 1 \\
\hline Safety signs and symbols & 84 & 3.69 & 0.834 & 2 \\
\hline Use, maintenance and replacement of protective equipment & 84 & 3.53 & 0.838 & 3 \\
\hline Procedures for the safe operation on site & 84 & 3.40 & 0.706 & 4 \\
\hline Site regulations & 84 & 3.38 & 0.924 & 5 \\
\hline Preventive/protective measures for risks/hazards on site & 84 & 3.35 & 0.861 & 6 \\
\hline Company's health and safety policy & 84 & 3.33 & 0.736 & 7 \\
\hline Best practices in the company & 84 & 3.31 & 0.853 & 8 \\
\hline Safety performance & 84 & 3.29 & 0.916 & 9 \\
\hline Site rules & 84 & 3.28 & 0.882 & 10 \\
\hline Knowledge of emergency procedures & 84 & 3.26 & 0.837 & 11 \\
\hline Company's philosophy & 84 & 3.23 & 0.939 & 12 \\
\hline The identities of the safety officer & 84 & 3.21 & 0.915 & 13 \\
\hline Procedures for resolving health and safety issues & 84 & 3.17 & 0.840 & 14 \\
\hline The potential risk of health \& safety of workers & 84 & 3.16 & 0.804 & 15 \\
\hline Nature of hazard in the workplace & 84 & 2.97 & 0.929 & 16 \\
\hline Safety inspection reports & 84 & 2.96 & 0.785 & 17 \\
\hline Disciplinary policy & 84 & 2.95 & 0.844 & 18 \\
\hline Location of hazard & 84 & 2.92 & 0.850 & 19 \\
\hline Injury and incident reporting procedures & 84 & 2.91 & 0.867 & 20 \\
\hline Accident statistics and records & 84 & 2.83 & 0.830 & 21 \\
\hline Accident investigation & 84 & 2.78 & 0.809 & 22 \\
\hline Minutes of safety review meetings & 84 & 2.68 & 0.789 & 23 \\
\hline Average mean score & & 3.19 & & \\
\hline
\end{tabular}


Table 3. Level of health and safety compliance of construction workers

\begin{tabular}{|c|c|c|c|c|}
\hline Variables & Valid & Mean Score & Standard Deviation & Rank \\
\hline Availability of first aid treatment & 84 & 3.33 & 0.718 & 1 \\
\hline Possession of basic safety training & 84 & 3.31 & 0.832 & 2 \\
\hline Safety equipment handled with utmost care & 84 & 3.29 & 1.003 & 3 \\
\hline Safety induction/project briefings for workers & 84 & 3.28 & 0.741 & 4 \\
\hline Prompt and adequate communication of potential risks to the workers & 84 & 3.26 & 0.938 & 5 \\
\hline Observation of safety rules and regulations on site. & 84 & 3.23 & 1.027 & 6 \\
\hline Maintenance and replacement of protective equipment & 84 & 3.21 & 0.893 & 7 \\
\hline Availability of safety alert/fire alarm in case of emergency & 84 & 3.17 & 0.817 & 8 \\
\hline Compulsory use of personal protective equipment on site & 84 & 3.16 & 0.808 & 9 \\
\hline Risk assessment & 84 & 2.97 & 0.822 & 10 \\
\hline $\begin{array}{c}\text { Availability of preventive and protective measures for the hazards on site/best } \\
\text { practices }\end{array}$ & 84 & 2.96 & 0.845 & 11 \\
\hline Information on the procedures for safe operation on site & 84 & 2.95 & 0.785 & 12 \\
\hline Availability of $\mathrm{H} \& \mathrm{~S}$ plan before commencement of construction project & 84 & 2.92 & 0.923 & 13 \\
\hline $\begin{array}{c}\text { Working environment always cleared and kept free from all objects that can } \\
\text { cause harm or injury }\end{array}$ & 84 & 2.91 & 0.781 & 14 \\
\hline Provision of warning signs/posters/photographs/notice board & 84 & 2.83 & 1.061 & 15 \\
\hline Provision of safety manual/handbook/ brochures/news letter & 84 & 2.78 & 0.838 & 16 \\
\hline Disciplinary policy & 84 & 2.68 & 0.906 & 17 \\
\hline Regular safety meeting & 84 & 2.66 & 1.215 & 18 \\
\hline Organizing safety conference/safety week & 84 & 2.66 & 0.968 & 19 \\
\hline Scaffolding properly and adequately fixed and inspected before mounting them & 84 & 2.37 & 0.944 & 20 \\
\hline Ladders fixed and adequately secured in position before ascending them & 84 & 2.34 & 0.912 & 21 \\
\hline Injury and incident reporting procedures & 84 & 2.14 & 0.954 & 22 \\
\hline Strict monitoring of safety policy & 84 & 2.12 & 0.907 & 23 \\
\hline Availability of emergency procedures & 84 & 2.03 & 1.043 & 24 \\
\hline Proper keeping of safety records & 84 & 2.00 & 0.718 & 25 \\
\hline Accident investigation & 84 & 1.94 & 0.912 & 26 \\
\hline Average mean score & & 2.47 & & \\
\hline
\end{tabular}

Table 4. Factors influencing level of compliance with H\&S information

\begin{tabular}{ccccc}
\hline Factors & Valid & Mean & Standard Deviation & Rank \\
\hline Management commitment & 84 & 4.11 & 0.900 & 1 \\
Lack of monitoring and enforcement & 84 & 4.06 & 0.873 & 2 \\
Cost of compliance & 84 & 4.03 & 0.822 & 3 \\
Fear of legal sanction & 84 & 3.91 & 0.853 & 4 \\
Weak legal structure & 84 & 3.89 & 0.963 & 5 \\
Higher profit margin & 84 & 3.83 & 0.857 & 6 \\
Availability of time/Time pressure & 84 & 3.83 & 0.954 & 7 \\
Belief and culture & 84 & 3.80 & 0.901 & 8 \\
Lack of awareness & 84 & 3.77 & 0.910 & 9 \\
Lack of adequate regulation & 84 & 3.74 & 0.950 & 10 \\
Absence of trained safety officer & 84 & 3.71 & 0.860 & 11 \\
Improper medium for disseminating information & 84 & 3.57 & 1.119 & 12 \\
Reputation of the firm & 84 & 3.51 & 0.919 & 13 \\
Tendering/contractual process & 84 & 3.49 & 0.818 & 14 \\
Negligence of human right & 84 & 3.17 & 0.785 & 15 \\
Perception of stakeholders & 84 & 2.94 & 1.027 & 16 \\
Client influence & 84 & 2.67 & 0.873 & 17 \\
Average mean score & & $\mathbf{3 . 4 4}$ & & \\
\hline
\end{tabular}

Table 5. Correlation between health and safety compliance and safety of workers

\begin{tabular}{ccccccc}
\hline Correlation Coefficient (r) & Nature of Association & T-test value & T-critical (3,0.05) & $\mathbf{R}^{\mathbf{2}}$ & P-value & Decision \\
\hline 0.69 & Strong positive correlation & 1.686 & 3.282 & 0.5141 & 0.197 & Accept $H_{O}$ \\
\hline
\end{tabular}

\subsection{Factors determining level of compliance of $\mathrm{H} \& S$ information on construction sites}

Compliance on H\&S information on construction sites depends upon many factors. These factors were identified and presented to the respondents to rank in order of influence. Management commitment was ranked first with MS of 4.11 followed by lack of monitoring and enforcement (MS of 4.06) as presented in Table 4 . The respondents also ranked cost of compliance (MS of 4.03), fear of legal sanction (MS of 3.91) and weak legal structure (MS of 3.89) as important factors influencing level of compliance with $\mathrm{H} \& \mathrm{~S}$ information. Other factors such as tendering/contractual process, negligence of human right, perception of stakeholders and client influence did not determine workers level of compliance with H\&S as indicated by the MS below average MS of 3.44. 
8.4 Relationship between compliance with H\&S information and safety of the workers

It is not enough to determine the level of H\&S knowledge and compliance among the construction workers and their impact on safety of workers, rather it is important to establish a relationship between level of $H \& S$ compliance and safety of workers. This would help to ascertain the degree of their association and how significance their relationship and influence were. In view of this, hypothesis on the significant relationship between construction workers' health and safety compliance and safety of workers was postulated as: There is no significant relationship between health and safety compliance and construction workers' safety. The result of the correlation analysis was presented in Table 5.

The result of analysis in Table 5 showed a strong positive correlation $(r=0.69)$ between the level of H\&S compliance and safety of workers. This implied that compliance with H\&S information in construction could lead to better safety of workers on site at least to some extent. This was attested by the value of the coefficient of determination $\left(\mathrm{R}^{2}=0.5141\right)$ which indicated that about $50.41 \%$ of variability could be achieved in the relationship.

However, when tested for the significance of the relationship, the result showed that t-calculated (1.686) was less than t-critical (3.282), at 5\% significance level $(\alpha=0.05)$ and (n-2) degree of freedom. This result therefore, revealed that there was no significant relationship between level of compliance with H\&S information and safety of workers. This was substantiated by the score of the p-value (0.197) which was greater than 0.05 and rendered the relationship insignificant despite the strong and positive correlation. The strong positive correlation ordinarily suggests that compliance with $H \& S$ information could lead to safety of workers on sites, until the significance of the relationship was tested. This result suggested that compliance with H\&S information alone could not ensure safety of workers because the relationship was insignificant. So therefore, even if there is adequate $H \& S$ information, knowledge and compliance among construction workers, it cannot translate to safety on construction sites.

\section{CONCLUSIONS}

This study has examined the level of knowledge and compliance with $\mathrm{H} \& \mathrm{~S}$ information, factors influencing the level of compliance and how they translate to safety of construction sites workers in Lagos State, Nigeria. This study has found out that there was average level of knowledge of $\mathrm{H} \& \mathrm{~S}$ information among the construction workers on sites in areas of first aid procedure, safety signs and symbols, use of personal protective equipment, procedure for safe operation and site regulations. It was also found that the level of compliance on this information was low. The result further revealed that management commitment and lack of monitoring and enforcement had influence on the level of compliance. The effect of compliance with $H \& S$ information on workers safety was high by establishing a strong positive correlation though not significant.

The study concluded that though there was positive relationship between level of $H \& S$ compliance and safety of workers though the relationship is not significant. This study further averred that compliance alone cannot substantially enhance safety of the workers even though it showed strong positive correlation with safety of the workers. This implies that there are other factors that are responsible for workers safety. Further research can be carried out to identify such factors.

\section{REFERENCES}

[1] Kolo, D.N. (2015). Safety issues involving workers on building construction sites in Nigeria: An Abuja study. MSc. Thesis in Civil Engineering, Eastern Mediterranean University, Gazimağusa, North Cyprus.

[2] Durdyev, S., Mohamed, S., Lay, M.L., Ismail, S. (2017). Key factors affecting construction safety performance in developing countries: Evidence from Cambodia. Construction Economics and Building, 17(4): 48-65. http://dx.doi.org/10.5130/AJCEB.v17i4.5596

[3] Kawuwa, A.S., Adamu, M.A., Shehu, A. Abubakar, I.M. (2018). Health and safety challenges on construction sites of Bauchi Metropolis. International Journal of Scientific and Research Publications, 8(1): 367-377.

[4] Okoye, P.U., Okolie, K.C., Ngwu, C. (2017). Multilevel safety intervention implementation strategies for Nigeria construction industry. Journal of Construction Engineering, 6(2): 1-14. https://doi.org/10.1155/2017/8496258

[5] Adebiyi, R.T., Babalola, O., Amuda-Yusuf, G., Olowa, T.O., Rasheed, S.A., Zubair, M.A. (2019). Level of adherence to health and safety regulations on construction sites in Nigeria. Proceedings of the $4^{\text {th }}$ The Nigerian Institute of Quantity Surveyors Research Conference, $10^{\text {th }}-12^{\text {th }}$ September, 2019, held at Enugu State University of Science and Technology, Enugu State, Nigeria.

[6] Arifuddin, R., Suraji, A., Latief, Y. (2019). Study of the causal factors of construction projects vulnerability to accidents. International Journal of Innovative Technology and Exploring Engineering, 8(6): 711-716.

[7] Okoye, P.U., Ezeokonkwo, J.U., Ezeokoli, F.O. (2016). Building construction workers' health and safety knowledge and compliance on site. Journal of Safety Engineering, $\quad 5(1)$ : 17-26. https://doi.org/10.5923/j.safety.20160501.03

[8] Akunyumu, S. (2016). A framework for on-site communication planning for construction managers in Ghana. M.Phil. Thesis Department of Building Technology, College of Art and Built Environment, Kwame Nkrumah University of Science and Technology, Kumasi, Ghana

[9] Udo, U.E., Usip, E.E., Asuquo, C.F. (2016). Effect of lack of adequate attention to safety measures on construction sites in Akwa Ibom State, Nigeria. Journal of Earth Sciences and Geotechnical Engineering, 6(1): 113-121.

[10] Ahmed, S. (2019). Causes and effects of accident at construction site: A study for the construction industry in Bangladesh. International Journal of Sustainable Construction Engineering and Technology, 10(2): 18-40.

[11] Fargnoli, M., Lombardi, M. (2019). Preliminary human safety assessment for the improvement of the behavioral aspects of safety climate in the construction industry. Buildings, $9(2)$ : 1-18. https://doi.org/10.3390/buildings9030069

[12] Kaur, D., Lilare, R.R., Rathod, N.D., Datta, B., Kaswan, 
P. (2019). An organization based cross-sectional study of occupational injuries among bridge construction workers in an urban area of Mumbai. International Journal of Community Medicine and Public Health, 6(3): 12111215. 6040.ijcmph20190613

[13] Muiruri, G., Mulinge, C. (2014). Health and safety management on construction projects sites in Kenya, A case study of construction projects in Nairobi country. International Journal of Occupational Safety, Environmental Health, 3(3): 50-61.

[14] Shafique, M., Rafiq, M. (2019). An overview of construction occupational accidents in Hong Kong: A recent trend and future perspectives. Applied Sciences, 9(2): 1-16. https://doi.org/10.3390/app9102069

[15] Biswas, G., Bhattacharya, A., Bhattacharya, R. (2017). Occupational health status of construction workers: A review. International Journal of Medical Science and Public Health, 6(4): 669-675. https://doi.org/10.5455/ijmsph.2017.0745302112016

[16] Sunindijo, R.Y., Zou, P.X.W. (2011). Political skill for developing construction safety climate. Journal of Construction Engineering Management, 138(5): 605-612. https://doi.org/10.1061/(ASCE)CO.1943-7862.0000482

[17] JISHA Japan Industrial Safety and Health Association. OSH Statistics in Japan. (2017). Available online: https://www.jisha.or.jp/english/statistics/, accessed on 19 December 2019.

[18] Health and Safety Executive, U.K. Fatal injuries arising from accidents at work in Great Britain. (2017). Available online: http://www.hse.gov.uk/statistics/, accessed on 20 December 2019.

[19] Bureau of Labor Statistics, U.S. (2017). Available online: https://www.bls.gov/opub/mlr/2017/home.htm, accessed on 5 March 2019.

[20] Labour Department. Occupational Safety and Health Statistics: Bulletin Issue No. 18. (2018). Available online: https://www.labour.gov.hk/eng/osh, accessed on 20 February, 2019.

[21] Workplace Safety and Health Institute. Global Estimates of Occupational Accidents and Work-Related Illnesses. (2017). Available online: http://www.icohweb.org/site/images/news/pdf/, accessed on 20 November 2019.

[22] Dejus, T. (2012). Accidents on construction sites and their reasons. Construction Technology Management 20. [CrossRef]

[23] Kwofie, E. (2015). Contribution of unique features of mass housing projects to project team communication performance. Ph.D. dissertation, Department of Building Technology Kwame Nkrumah University of Science and Technology, Kumasi, Ghana.

[24] Amissah, J., Badu, E., Agyei-Baffour, P. Nakua, E.K., Mensah, I. (2019). Predisposing factors influencing occupational injury among frontline building construction workers in Ghana. BMC Research Notes, 12: 728. https://doi.org/10.1186/s13104-019-4744-8

[25] Machfudiyanto, R.A., Latief, Y., Arifuddin, R., Yogiswara, Y. (2017). Identification of safety culture dimensions based on the implementation of $\mathrm{OSH}$ management system in construction company. Procedia Engineering, 171: 405-412. https://doi.org/10.1016/j.proeng.2017.01.350

[26] Kheni, A. (2008). Impact of health and safety management on safety performance of small and medium-sized construction businesses in Ghana. P.hD. dissertation Loughborough University, UK.

[27] Farooqi, R.U., Arif, F., Rafeeqi, S.F.A. (2008). Safety performance in construction industry of Pakistan. First International Conference on Construction in Developing Country Advancing and Integrating Construction Education, Research \& Practice Karachi, Pakistan, pp. 74-87.

[28] Agwu, M.O., Olele, H.E. (2014). Fatalities in the Nigerian construction industry: A case of poor safety culture. British Journal of Economics: Management and Trade, 3(4): 431-454. https://doi.org/10.9734/BJEMT/2014/6439

[29] Adeogun, B.K., Okafor, C.C. (2013). Occupational health, safety and environment (HSE) trend in Nigeria. Journal of Environmental Science, Management and Engineering Research, 2(1): 24-29.

[30] Umeokafor, N.I., Isaac, D., Jones, K.G., Umeadi, B. (2014). Enforcement of occupational safety and health regulations in Nigeria: An exploration. European Scientific Journal, Special Edition, 3: 93-104.

[31] Muhammad, B.A., Abdulateef, I., Ladi, B.D. (2015). Assessment of cost impact in health and safety on construction projects. American Journal of Engineering Research, 4(3): 25-30. https://doi.org/10.6084/m9.figshare.1344744.v1

[32] Adebiyi, R.T., Babalola, O., Amuda-yusuf, G., Rasheed, S.A. (2019). Assessment of health and safety information on construction sites in Nigeria. Proceedings of Environmental Design and Management International Conference $20^{\text {th }}-22^{\text {nd }}$ May, 2019, Obafemi Awolowo University, Ile-Ife, Nigeria, pp. 138-148.

[33] Agwu, M.O. (2012). Total safety management: A strategy for improving organizational performance in selected construction companies in Nigeria. International Journal of Business and Social Science, 3(20): 210-217.

[34] Kayumba, A. (2013). Editorial: Construction work and occupational safety and health. African Newsletter on Occupational Health and Safety, 23(3): 51.

[35] Asanka, W.A., Ranasinghe, M. (2015). Study on the impact of accidents on construction projects. Proceedings of $6^{\text {th }}$ International Conference on Structural Engineering and Construction Management, Kandy, Sri, Lanka, $11^{\text {th }}-13^{\text {th }}$ December 2015.

[36] Bust P., Finneran A., Hartley R., Gibb A. (2014). Health and safety knowledge in complex networked organizations: Training the chain. Proceeding CIB W099 Achieving Sustainable Construction Health and Safety, Lund, Sweden, pp. 50-61.

[37] Roberts, J. (2000). From know-how to show-how? Questioning the role of information and communication technologies in knowledge transfer. Technology Analysis and Strategic Management, 12(4): 429-443. https://doi.org/10.1080/713698499

[38] Akinwale, A.A., Olusanya, O.A. (2016). Implications of occupational health and safety intelligence in Nigeria. Journal of Global Health Care Systems, 6(1): 1-13.

[39] Akpan, E.I. (2011). Effective safety and health management policy for improved performance of organizations in Africa. International Journal of Business and Management, 6(3): 56-63. https://doi.org/10.5539/ijbm.v6n3p159

[40] Kumar, S., Bansal, V.K. (2013). Construction safety 
knowledge for practitioners in the construction industry. Journal of Frontiers in Construction Engineering, 2(2): $34-42$.

[41] Kamar, I.F.M., Lop, N.S., Salleh, N.M., Mamter, S., Suhaimi, H.A. (2014). Contractor's awareness on occupational safety and health (OSH) management systems in construction industry. E3S Web of Conferences.

https://doi.org/10.1051/e3sconf/20140301019

[42] Sunindijo, R.Y., Zou, P.X. (2014). An integrated framework for strategic safety management in construction \& engineering. Proceedings. CIB W099 Achieving Sustainable Construction Health and Safety,
Lund, Sweden, pp. 63-74.

[43] Williams, O.S., Hamid, R.A., Misnan, M.S. (2018). Accident causal factors on the building construction sites: A review. International Journal of Built Environment and Sustainability, $5(1)$ :

78-92. https://doi.org/10.11113/ijbes.v5.n1.248

[44] Opawole, A., Alao, O.O. (2015). Performance evaluation of measured quantities for procurement of engineering services in building works. Proceedings of Environmental Design and Management International Conference (EDMIC) $9^{\text {th }}-12^{\text {th }}$ March, 2015, Obafemi Awolowo University, Ile-Ife, Nigeria, pp. 111-118. 